\title{
Research on the Role of Chinese Calligraphy in the Artistic Creation
}

\author{
Chengzhi Yu \\ School of Jingdezhen Ceramic University College of Science and Technology, Jiangxi, 333000, \\ China
}

376597000@qq.com

Keywords: Chinese calligraphy; art; creation.

\begin{abstract}
Chinese calligraphy is the art of writing Chinese characters. Along with the development of society, the art of calligraphy is widely used in the field of design, which provides a broad thinking space for the design, inspires more inspiration, and adds colorful visual elements. Through the discussion of the function, principle and design method of the calligraphy art in the art creation, the purpose is to advocate the application of Chinese calligraphy in the creation of art to explore the Chinese design "Nationalization".
\end{abstract}

\section{Introduction}

Chinese characters are the product of image thinking and rational thinking in combination in the Chinese nation for thousands of years, and one of the important carrier of Chinese civilization being handed down. China calligraphy style is the art of writing Chinese characters, accompanied by the development of Chinese characters, the evolution of the seal character, official script, cursive script and various kinds of style occurred [1]. In the vicissitudes of thousands of years, it is endowed with broad and profound cultural connotation and incomparable artistic charm, with distinctive ethnic characteristics.

With the development of society, the art of calligraphy has been applied in the field of modern art, which has added colorful visual elements to the design, inspired more inspiration, and provided a broad space for thinking. Therefore, we should use modern design method, combined with the art of calligraphy aesthetic principle and deep cultural connotation, the calligraphy elements are applied in modern design, to explore the design style with China characteristics. In order to elaborate conveniently, the word "calligraphy font" is put forward, which is used to be different from the art word that the computer standardly produce, and the calligraphy font specially refers to the font written by people by using brush.

\section{Functions of Chinese Calligraphy in the Creation of Art}

\subsection{Communication Function}

From the perspective of information dissemination, text has phonetic, phenotype and ideographic functions, and the Chinese characters is the typical ideographic characters developed on the basis of pictographic characters. Calligraphy with Chinese characters as the carrier, the main function of it in the art creation is to convey information. From the perspective of semiotics, calligraphy text is a kind of special visual symbol system, which has an important function of the "signified" and "signifier" [2]. From the text level, ideographic feature of text symbols can directly convey the intention of design works and all kinds of information to the public, namely "signified"; from the artistic perspective, as a traditional art, its morphology, structure and style also has multiple meanings, through repeat exploration of the calligraphy font, we can also understand its more implied meanings, namely "signifier". As a result, the calligraphy as a communication symbol has the function of "double decoding".

There is no doubt that applying the calligraphy art in art creation, not only can directly convey the basic information of the text, but also express the profound cultural heritage information to shape the corporate image and create a brand. Chinese University, hospital of traditional Chinese medicine and 
so on especially love using calligraphy to make the title, such as Peking University and Beijing Tongrentang. Chinese well-known enterprises design and product packaging design are also keen on using the calligraphy design elements, such as liquor, tea, moon cake, dumplings everywhere. The calligraphy logo of "Peking University" and "Beijing Tong Ren Tang" is shown in Figure 1 [3].
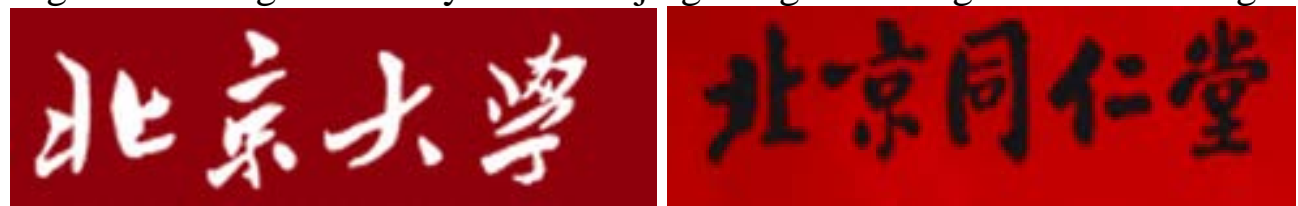

Figure 1."Peking University" and "Beijing Tong Ren Tang" calligraphy logo

\subsection{Aesthetic Function}

As a visual communication sign, calligraphy not only has the function of conveying information, but also has the function of aesthetic function. The beauty of lines, beauty of structure, and beauty of shape of calligraphy and rhythm and overall performance of itself have brought people with visual beauty, obtaining cheerful aesthetic experience. The seal character, official script and regular script with neat strokes and stable structure, giving people a stable and dignified feeling; running script is characterized by static and dynamic combination, clever and lively; but the cursive with potential indulgence and continuous unrestrained, gives people with passion and feeling in high spirit. Therefore, the calligraphy as a design element is applied to a variety of design types can also give consumers a sense of beauty.

Text image is a kind of common artistic technique. The so-called text image, is to evolve the shape (the whole or partial) of calligraphy font into graphics [4]. Combination of text and graphics make the design ideas to get more free space to play, which not only can play a role in inducing sight and arousing consumers' aesthetic consciousness, but also renders artistic conception and gives a visual aesthetic enjoyment, to stimulate consumers' sentiment and interest.

\section{Design Method of Chinese Calligraphy in the Artistic Creation}

\subsection{Borrowing and Reference}

Borrowing, or called misappropriation, refers to the method of taking the whole or part of classical calligraphy works as the design elements to copy in the design. For instance, Mao Zedong's calligraphy is well known. In the design, some of his calligraphy fonts are borrowed as the design elements of a brand logo, such as the "red flag" car logo design, "Long March" hotel logo design and so on.

Reference and contrast. The core of reference is to refer to the calligraphy form model, regular borrowing, from this to another, and infer other things from one fact. In artistic creation, the key of reference is to repeatedly review calligraphic strokes, structure and other characteristics, and combined with the design object to conceive. On the basis of maintaining the basic strokes of calligraphy font or basic structure unchanged, a feature of calligraphy is creatively used in art creation, which presents a new art appearance of design object.

\subsection{Deconstruction and Reconstruction}

The original meaning of deconstruction is decomposition, digestion, and disassembly and so on. Deconstruction takes a famous calligrapher's works as the prototype, and according to the needs of the design, the structure is dismantled so that it is fragmented. The reconstruction is based on the "Gestalt theory" [5], original scattered strokes and radicals, and even calligraphy materials, tools and other elements are re-combined according to the requirements of the expression of specific design objects, to obtain new knowledge and experience.

\subsection{Decoration}

The decoration can be divided into two kinds; the first kind is to make other visual elements (such as auspicious pattern) collectively combining as a calligraphy style. For example, strokes of regular scripts of $\mathrm{Fu}, \mathrm{Lu}$, Shou, and $\mathrm{Xi}$ in Chinese folk pattern are decorated by pomegranate, peony, bats, cranes, etc, reflecting the Chinese desire of enjoying the festive [6]. The second is to take the calligraphy text as a visual element, to decorate certain pattern, where the calligraphy and text play a 
kind of beautification effect like the texture. The ancient architectural design and interior decoration in China especially like using calligraphy and paintings, calligraphy has played a role of highlighting in the design. "Fu, Lu, Shou, and Xi" calligraphy decoration works is shown in Figure 2.
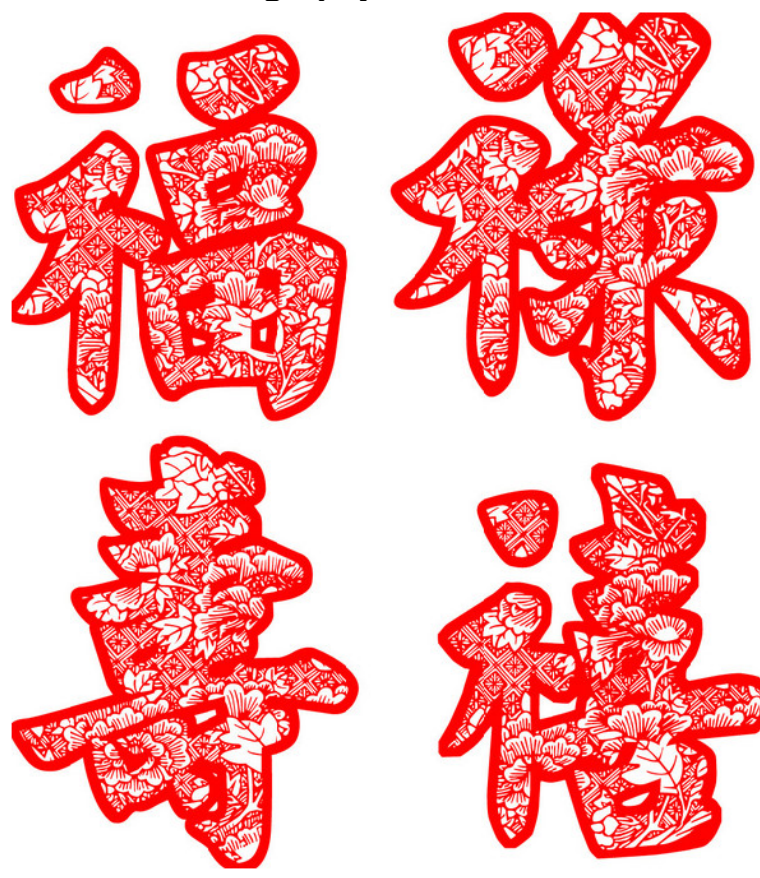

\subsection{Creation}

Figure 2. Calligraphy decoration works of "Fu, Lu, Shou, and $\mathrm{Xi"}$

Creation is the most basic method of artistic creation, and it is the basis of the method of borrowing, reference, deconstruction, decoration and so on. The calligraphy text needs to be new and to be different in conception in the design. No matter the packaging, decoration, signs, books, posters, advertising or environmental design, all of them can draw on the form of calligraphy art, on the basis of the "form" to grasp the unique characteristics of Chinese characters and inner spirit, and carry out extensive association and imagination, breaking the limitations of design object surface impression [7]. Make up for the deficiency of the fine arts of rigid font and the lack of human touch by adopting various calligraphy fonts, to broaden the expression forms and effects of modern art creation.

\section{Role of Chinese Calligraphy in the Creation of Art}

\subsection{Role of Chinese Calligraphy in the Creation of Signs}

Chinese character is the main carrier body of calligraphy art and practicality, and it is also an important design element of graphic design. The current lots of outstanding design works all regard the calligraphy characters as the main design elements. For example, China bank mark is to combine coins and Chinese characters "zhong", which highlights the function of the bank, and makes the sign full of tension and heavy feeling; 2008 Olympic Games emblem is designed by the seal with quaint decoration beauty, Chinese cultural heritage for thousands of years and Olympic modern elements are perfectly combined, showing the traditional aesthetic idea of subtle, elegant, and simple [8], thus reflecting the Beijing Olympic humanistic spirit; in addition, many liquor companies logo design also use the art of calligraphy, so as to highlight the long cultural connotation of enterprise brand. "Bank of China" logo is shown in Figure 3. 

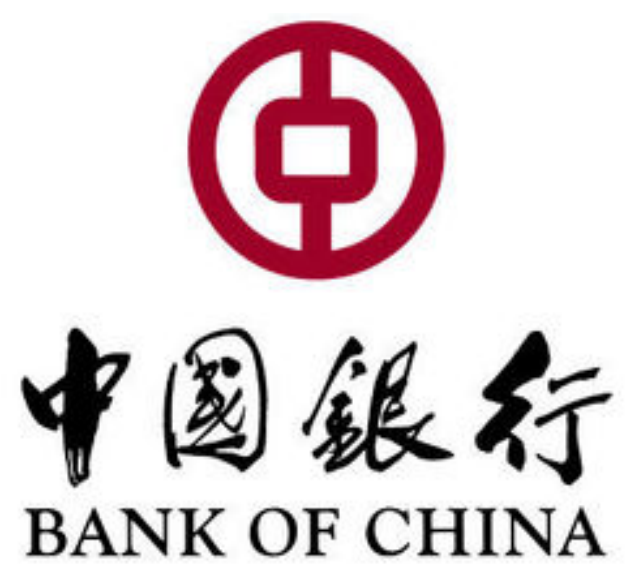

Figure 3. Logo of "Bank of China"

\subsection{Role of Chinese Calligraphy in the Creation of Print Media}

The art of calligraphy is a unique art, calligraphy pen method, dynamic, rhythm, tone and so on are used in graphic design, to create oriental beauty with cultural connotation. In modern graphic design, the beauty of spirit is an important goal that designers pursue. For example, the poster "At ease" designed by Jin Daiqiang, uses ink lines with freely flowing style of writing showing a harmonious cultural conception. The poster "At ease" designed by Jin Daiqiang is shown in Figure 4.
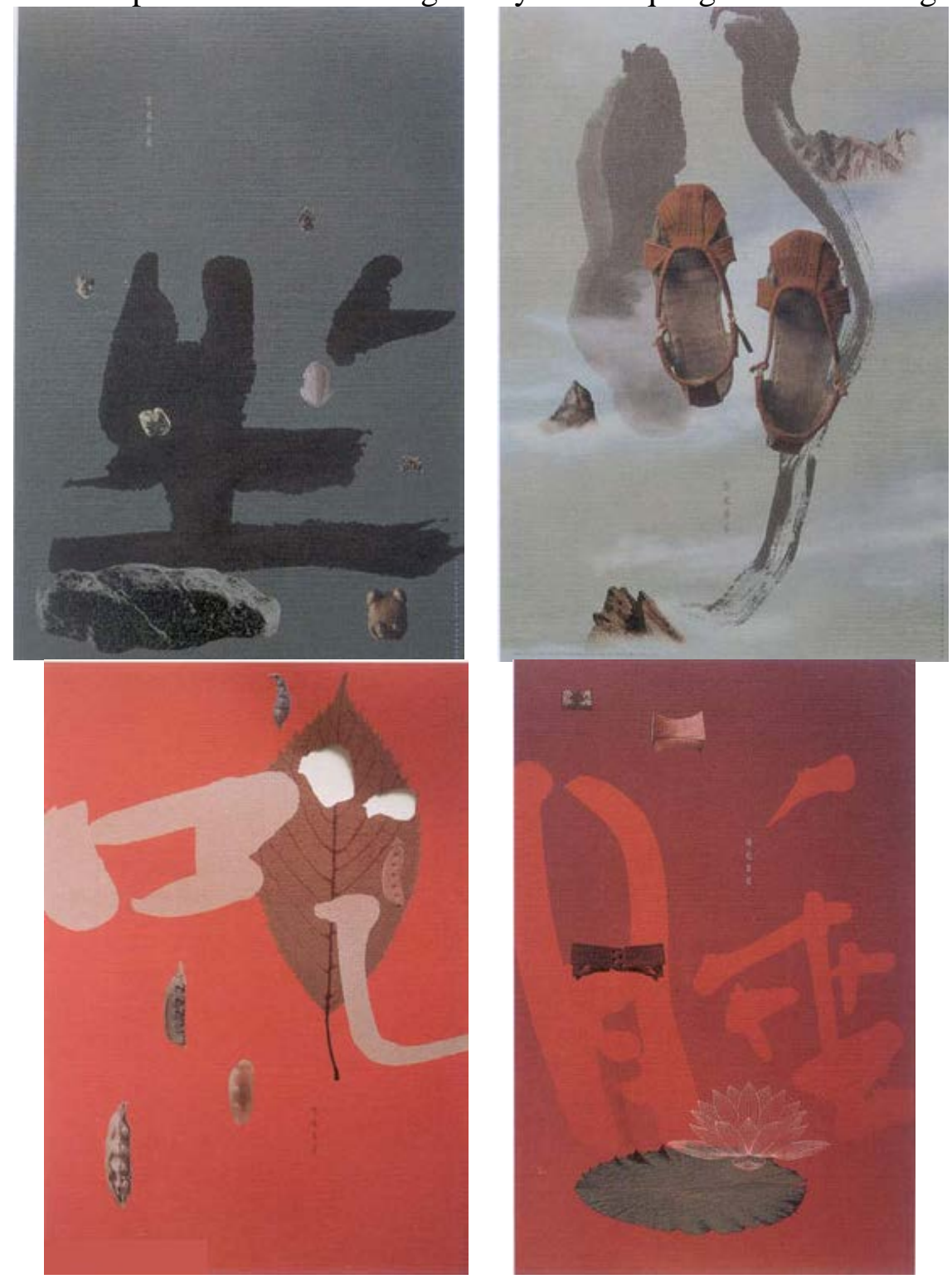

Figure 4. The poster "At ease" designed by Jin Daiqiang 
CCTV news channel image packing is the typical art of calligraphy used in the print media in the design, and the design combines the art of calligraphy and media design, which embodies the cultural charm of the art of calligraphy and effectively inherits the traditional national culture [9]. The art of calligraphy not only has a wide range of applications in the media packaging, it is also widely used in the modern film design, such as the movie posters and film titles design used many calligraphy elements. The pen shaped cursive is without stop, having a strong artistic color, applied to the movie poster design, which can overcome the defects of printed monotone so that the design works have cultural characteristics and connotations. Although the film title design early is rough, the calligraphy font contains the movie theme has left a deep impression to the audience, such as the production of "Curse of the Golden Flower" "The banquet" "Hero" and other films titles [10], the application of the calligraphy font becomes extremely delicate, and this kind of design has more cultural meaning than the print font.

\subsection{Role of Chinese Calligraphy in the Creation of Commodity Packaging}

The calligraphy art is widely used in the modern commercial packaging design, and becomes the symbol of the grade of commodity culture. The use of calligraphy font in the packaging design can not only add the unique qualities of packaging and local cultural atmosphere, but also plays a role of decoration and publicity. And because the consumer object of the goods and the market positioning are different, the calligraphy font selected in the packaging design will be different. In the tea bag, it will often see a very elegant word "Cha" [11]; and in children's products are always with a lively sense of joy and sense of intimacy cursive writing; in the books with strong cultural sense, often use standard script writing, and in electronic products packaging, simple and eye-catching fonts are used.

\section{Conclusion}

The art of calligraphy is the essence of Chinese traditional art, containing the creation spirit and collective wisdom of Chinese nation, whose cultural essence is a valuable resource for graphic design art creation. In today's cultural globalization, western culture and values have penetrated into all aspects of our lives, affecting our values and ways of thinking, which makes the traditional culture trapped in a survival crisis [12]. To this end, we are supposed to carry forward the excellent traditional culture, and integrate calligraphy art into the modern graphic design, to enhance the level of modern design art and show the charm of Chinese culture.

\section{References}

[1] Leung K. A 27 exploratory study on nurturing students' cultural awareness in a Hong Kong primary school through learning Chinese calligraphy with a spiritual perspective [J]. Teaching for Tomorrow Today, 2015: 185.

[2] Churchill P. Mao Zedong, the masses, and the art of calligraphy: Big-Character posters during the Cultural Revolution [J]. Concordia Undergraduate Journal of Art History, 2014.

[3] Lam N W. Comparison of Chinese Calligraphy and Ink Painting Brushes with Western Water-Media Painting Brushes[C]/Proceedings of the 2nd International Colloquium of Art and Design Education Research (i-CADER 2015). Springer Singapore, 2016: 571-576.

[4] Yang N. The aesthetic experience of Zen in the art of Chinese calligraphy [J]. Journal of Jiamusi Education Institute, 2013, 8: 063.

[5] Du X, Wu J, Xia Y. Bayesian relevance feedback based Chinese calligraphy character synthesis [C]//Multimedia and Expo (ICME), 2016 IEEE International Conference on. IEEE, 2016: 1-6.

[6] Zhou Q B, Zhang J, Edelheim J R. Rethinking traditional Chinese culture: A consumer-based model regarding the authenticity of Chinese calligraphic landscape [J]. Tourism Management, 2013, 36: 99-112. 
[7] Sun Y, Qian H, Xu Y. A geometric approach to stroke extraction for the Chinese calligraphy robot[C]//2014 IEEE International Conference on Robotics and Automation (ICRA). IEEE, 2014: 3207-3212.

[8] Wang $\mathrm{M}, \mathrm{Fu} \mathrm{Q}$, Wang $\mathrm{X}$, et al. Evaluation of Chinese Calligraphy by Using DBSC Vectorization and ICP Algorithm [J]. Mathematical Problems in Engineering, 2016, 2016.

[9] Huang Z K, Li Z H, Huang H, et al. Comparison of different image denoising algorithms for Chinese calligraphy images [J]. Neuro-computing, 2016, 188: 102-112.

[10] Zhu G H. Advantages and Strategies of Tourism Landscape Development in Harmony with Traditional Calligraphy Art-The Hometown of Confucius and Mencius as an Example [C]//Applied Mechanics and Materials. Trans Tech Publications, 2014, 675: 1266-1270.

[11] Xu P, Zheng X, Chang X, et al. Artistic information extraction from Chinese calligraphy works via Shear-Guided filter [J]. Journal of Visual Communication and Image Representation, 2016, 40: 791-807.

[12] Kwok Y N. The role of physicality and materiality in Europeans' global sensibilities when responding to Chinese Painting and Calligraphy after 1600 and before 1860 [C]//David Nichol Smith Seminar in 18th-Century Studies. The University of Sydney., 2014. 